\title{
Characterization by Transmission Electron Microscopy of Palladium Nanoparticles Obtained by Thermal Reduction
}

\author{
Jhon F. Sánchez M. ${ }^{1 *}$, Cecilia Gutierrez-Ayesta ${ }^{2}$, María A. Floridia A. ${ }^{3}$ and Miguel D. Sánchez ${ }^{1}$ \\ 1. IfiSur, Conicet, Depto. Física - UNS. \\ 2. Laboratorio de Microscopía Electrónica, Conicet. Depto. Biología Bioquímica y Farmacia - UNS. \\ 3. Y-tec, YPF Tecnología. Laboratorio de Microscopía. \\ *Corresponding author: sanchezmorales@ifisur-conicet.gob.ar
}

The results show the electron microscopy characterization of palladium nanoparticles (NPs) obtained by the polyol [1,2] method at different temperatures [3]. The $\mathrm{PdCl}_{2} /$ ethylene glycol colloidal solution was heated at different temperatures. The heating would increase the reduction rate and avoid the chemical reducing agents. This condition would improve the quality of the material obtained, avoiding the appearance of nanoparticles pollutants during the synthesis. The temperature's increase would have effects on the growth and nucleation kinetics, and also on the morphology of the nanoparticles. The reduction process was performed with temperatures between $25-175^{\circ} \mathrm{C}$ and at different reaction times. The synthesis was followed by (UV-vis) spectroscopy to determinate the reduction percentage of the palladium species. The UV-vis spectrum was obtained with Ocean optics USB2000 spectrophotometer.

The obtained material was characterized by X-ray diffraction (DRX) to determinate the apparent crystallite size and to analyse the composition. The size of the synthesized particles was determinated by electronic microscopy, showing an aggregate material with different size (10-30 $\mathrm{nm})$. These analyses were performed with a Transmission Electron Microscope JEOL-100-CX-II, operated at $100 \mathrm{kV}$. A high-resolution FEI Talos F200X ${ }^{\mathrm{TM}}$ (Thermo Scientific ${ }^{\mathrm{TM}}$ ) with a Super-X (Energy Dispersive Spectrum) equipped with four detectors without windows was also employed. This microscope was operated at $20 \mathrm{kV}$ at high-resolution mode (HRTEM). High quality nanoparticles were obtained by thermal decomposition. The $\mathrm{Pd}(\mathrm{II})$ ions complete reduction was obtained only with temperatures near the boiling point of ethylene glycol. However, the crystallite size was close to $30 \mathrm{~nm}$. The XRD analyses showed that the temperature would not affect the crystallite's size distribution. 
References:

[1] L.J. Chen et al., J. Colloid Interface Sci. 297 (2006), p. 143.

[2] H. Yue et al., Chem. Soc. Rev. 41 (2012), p. 4218.

[3] H. Hei et al., Soft Nanosci. Lett. 2(3) (2012), p. 34.

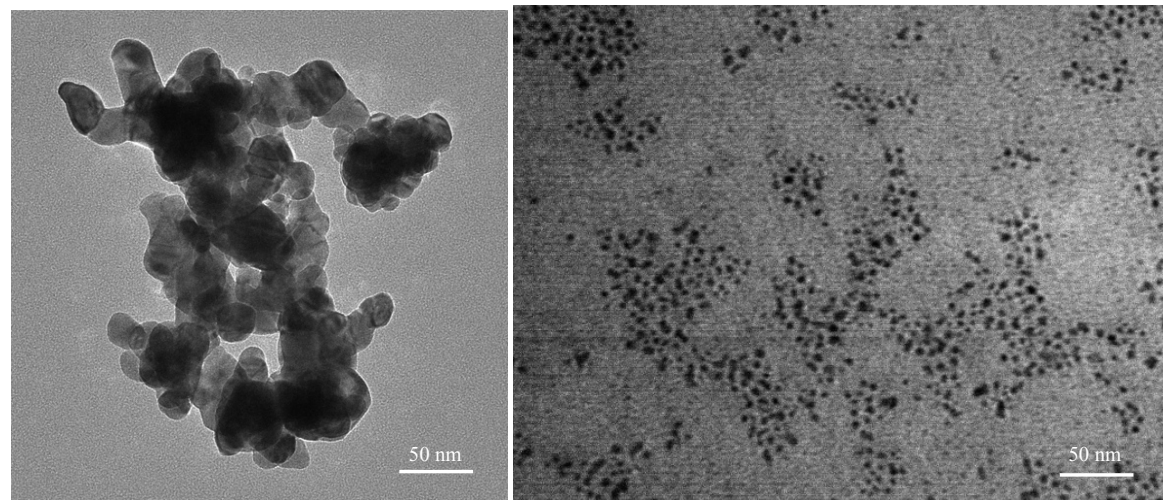

Figure 1. Palladium nanoparticles obtained at $120^{\circ} \mathrm{C}$. (scale: $50 \mathrm{~nm}$ ) 